\title{
Demonstration of Gamification in Education for Understanding Artificial Intelligence Principles at Elementary School Level
}

\author{
Eunsun Choi, $\quad$ Major in Computer Education, Faculty of Science Education, Graduate School, Jeju National \\ University, Jeju Special Self-Governing Province, 63294, Korea, namjepark@jejunu.ac.kr \\ Namje Park, Department of Computer Education, Teachers College, Jeju National University, Jeju Special \\ Self-Governing Province, 63294, Korea. \\ ${ }^{*}$ Corresponding author
}

\begin{abstract}
Artificial intelligence(AI) has emerged as an important key issue in 2020, as predict ed by the prospect that those who conquer AI will hold the hegemony of the world in the future which is why the world is paying attention to AI. However, the research on effective ways for students to better understand and utilize AI is in its infancy globally. It is crucial t o educate young students(k-1 to 6) AI principles through an efficient method, as part of ICT education. In this paper, we suggest a gamification education based on board games as a w ay to promote elementary school students' motivation to learn AI, which is still ambiguous a nd challenging for adults to understand. In addition, the proposed education method aims to demonstrate the effectiveness of education by analyzing the satisfaction of the results of educ ation conducted in elementary schools. An interesting way to teach relatively complex concept $\mathrm{s}$ of AI has been designed, using board games that elementary school students like. The boar $\mathrm{d}$ game-based gamification curriculum proposed in this paper has been piloted, resulting in el ementary students getting a better understanding of AI than before education and an average satisfaction of 4.73 out of 5 . Gamification in education is an effective means to boost stude nts' interest in their studies. The gamification education proposed in this paper is expected $t$ $o$ educate early on the concept of AI emerging in information science so that students can b ecome more interested in AI in the future.
\end{abstract}

Keywords: Gamification, Artificial Intelligence Education, Computational Thinking, Elementary ed ucation, Information and Communications Technologies

Received: 08.12.2020 $\quad$ Accepted: 10.01.2021 Published: 06.02.2021

\section{INTRODUCTION}

The first thing to notice about the dangers of COVID-19, which shocked people worldwide in 2020, was the AI robot, not the Chinese health authorities. It is no exaggeration to say that AI is now inseparable from humanity, as COVID-19 prediction, diagnosis and non-face-to-face care are all possible with AI. Especially in the world where AI native children will live in the future. It is expected that it will be more challenging to live without knowing AI. In order to teach professional and sophisticated skills to elementary school students, in addition to simply regulating the difficulty, they should present ways to increase students' participation and encourage interest. Gamification in education combines game elements and game design techniques into education to be enjoyed like a game. Gamification also has the advantage of strategically designing both the interaction and the results of the process. It was investigated the effect of gamification on learning, engagement, and enjoyment. Gamification in education increased students' learning levels. It was also found that gamification increased both cognitive load and achievement levels, and most students think positively about gamification education. This study proposes a way to make elementary school students learn AI through games, a vital element of the Fourth Industrial Revolution, and aims to help learners familiarize themselves with the concept of AI by enabling them to learn the principles of AI interestingly[1,2].

\section{Related Research}

\subsection{Gamification in Education}

Before 2000, the concept of incorporating games into something existed, but in 2002 the user interface (UI), which was mainly used in games, was incorporated into electronic devices such as Automated Teller 
Machines, vending machines, and smart phones, and then Nick Pelling began to use the word 'Gamification' for the first time. Ever since then, Gamification 2013 was held at Waterloo University in 2013, and the research on Gamification was accelerated. Gamification has also brought about changes in traditional teaching methods. According to a study, game mechanics can increase learners' ability to learn new skills by $40 \%$, and a game-style approach can create a high level of commitment and motivation for learners. Gamification in education can be seen as an effective way to educate students to create a desire for learning and to change into action.

\subsection{AI Education}

AI education can be seen as one of the crucial indicators for national development. It is because a country that makes good use of AI will have enough influence to change the game around the world. With the importance of AI emerging, so many places teach about AI, including elementary, middle, high schools, institutes, universities, and websites. Furthermore, many websites offer free AI online courses so that learners can learn about AI anywhere with their electronic devices. However, what concepts or principles of AI should be taught in training may vary depending on the students' age, level of learning, occupation Etc. Adults working in the IT field or performing professional tasks using AI may need to focus on specific principles and skills of AI, but children and students who are unfamiliar with AI need a guideline when they learn about it. The U.S., which has the highest level of competitiveness AI as of 2020, has developed guidelines for AI education for elementary, middle, and high school students through the AI4K12 initiative jointly working by the Computer Science Teachers Association and Association for the Advancement of Artificial Intelligence. They provide the five big idea framework for AI content categories to be learned in elementary, middle, and high schools. (see table 1).

Besides, the contents of AI education for elementary school students are proposed in three ways: understanding AI, understanding AI principles, and application of AI. To explain the principle or an ambiguous concept, a method that generates an interest based on play and hands-on learning can be useful[3,4]. (see table 2).

Table1 Design of test problems AI4K12's five big idea framework

\begin{tabular}{|c|c|c|c|c|c|c|}
\hline Big Idea & Perception & & $\begin{array}{l}\text { Representation } \\
\text { and Reasoning }\end{array}$ & Learning & $\begin{array}{l}\text { Natural } \\
\text { Interaction }\end{array}$ & $\begin{array}{l}\text { Societal } \\
\text { Impact }\end{array}$ \\
\hline Concept & $\begin{array}{l}\text { Computers } \\
\text { sensors } \\
\text { perceive } \\
\text { world. }\end{array}$ & $\begin{array}{r}\text { use } \\
\text { to } \\
\text { the }\end{array}$ & $\begin{array}{l}\text { The agent } \\
\text { maintains the } \\
\text { representation of } \\
\text { the world and } \\
\text { uses it. }\end{array}$ & $\begin{array}{l}\text { Computers } \\
\text { learn through } \\
\text { data. }\end{array}$ & $\begin{array}{l}\text { Intelligent } \\
\text { agents need } \\
\text { knowledge to } \\
\text { interact with } \\
\text { people. }\end{array}$ & $\begin{array}{l}\text { AI can have } \\
\text { both positive } \\
\text { and negative } \\
\text { effects on } \\
\text { society. }\end{array}$ \\
\hline
\end{tabular}




\begin{tabular}{|c|c|c|c|c|c|}
\hline $\begin{array}{l}\text { Education } \\
\text { Content }\end{array}$ & $\begin{array}{l}(\mathrm{K}-2) \\
\text { Communicate } \\
\text { with Alexa or Sir } \\
(3-5) \\
\text { Understand how } \\
\text { sensor inputs are } \\
\text { converted to } \\
\text { digital signals } \\
(6-8) \\
\text { Develop program } \\
\text { using sensors } \\
\text { (9-12) } \\
\text { Acquire } \\
\text { background } \\
\text { knowledge of } \\
\text { various computer } \\
\text { perception }\end{array}$ & $\begin{array}{l}(\mathrm{K}-2) \\
\text { Learn how to use } \\
\text { the decision tree } \\
(3-5) \\
\text { Represent animal } \\
\text { classification } \\
\text { system using tree } \\
(6-8) \\
\text { Design the home } \\
\text { location as a } \\
\text { graph model and } \\
\text { infer the } \\
\text { minimum path } \\
\text { (9-12) } \\
\text { Express Tic-Tac- } \\
\text { Toe game as a } \\
\text { search tree }\end{array}$ & $\begin{array}{l}(\mathrm{K}-2) \\
\text { Use the image } \\
\text { recognition } \\
\text { tool } \\
(3-5) \\
\text { Understand } \\
\text { three Methods } \\
\text { of machine } \\
\text { learning } \\
(6-8) \\
\text { Resolving } \\
\text { training data } \\
\text { deviations } \\
\text { (9-12) } \\
\text { Train Neural } \\
\text { Network } \\
\text { Training and } \\
\text { Experience } \\
\text { simple } \\
\text { Algorithm }\end{array}$ & $\begin{array}{l}(\mathrm{K}-2) \\
\text { Identify } \\
\text { positive and } \\
\text { negative } \\
\text { words } \\
(3-5) \\
\text { Understand } \\
\text { emotions } \\
\text { through } \\
\text { intonation and } \\
\text { facial } \\
\text { expression } \\
\text { (6-8) } \\
\text { Create } \\
\text { simple } \\
\text { Chatbot } \\
\text { (9-12) } \\
\text { Handle } \\
\text { ambiguous } \\
\text { expressions } \\
\text { with } \\
\text { sentence } \\
\text { analyzer }\end{array}$ & $\begin{array}{l}(\mathrm{K}-2) \\
\text { Discuss on AI } \\
\text { Cases in real } \\
\text { life } \\
(3-5) \\
\text { Describe the } \\
\text { impact of AI } \\
\text { bias } \\
(6-8) \\
\text { Explain the } \\
\text { reason for the } \\
\text { unexpected } \\
\text { result of AI } \\
\text { (9-12) } \\
\text { Research the } \\
\text { AI application } \\
\text { plan for } \\
\text { solving social } \\
\text { problems }\end{array}$ \\
\hline
\end{tabular}

Table 2 Contents and Method of AI Education for Elementary School students

\begin{tabular}{|c|c|c|}
\hline Content & Element & Teaching Method \\
\hline Understanding of AI & $\begin{array}{l}\cdot \text { What is AI? } \\
\cdot \text { AI and our life } \\
\cdot \text { AI and ethics }\end{array}$ & - \\
\hline $\begin{array}{l}\text { Understanding of AI } \\
\text { principles }\end{array}$ & $\begin{array}{l}\cdot \text { Data literacy } \\
\cdot \text { Linear regression } \\
\cdot \text { Error correction } \\
\cdot \text { Neural network } \\
\cdot \text { Deep-learning model }\end{array}$ & $\begin{array}{l}\cdot \text { Unplugged } \\
\cdot \text { Board-game } \\
\cdot \text { Physical activity }\end{array}$ \\
\hline Application of AI & - Problem solving with AI & $\begin{array}{l}\cdot \text { Project-based learning } \\
\cdot \text { Practical exercise }\end{array}$ \\
\hline
\end{tabular}

\section{Suggested teaching method}

\subsection{AI game design process}

AI principles teaching methods using gamification proposed in this study were designed by applying general procedures for game design proposed by Livingston\&Stoll and an instructional model proposed by Dick\& Carey. (see figure 1 ).

[Step 1] Set the learning objective

Among the AI principles, the understanding of the Convolutional Neural Network (CNN) is a goal of study. CNN is a concept that is mainly used in speech or image recognition. It is a kind of artificial neural network that is mainly studied in various imaging processing, computer vision fields, such as processing 
data through a multidimensional arrangement, extracting high levels of abstract information, or drawing pictures with new textures.

[Step 2] Select the kind of game

The type of game is a board game, and the one who finds the most characters and typical characteristics on the board wins.

[Step 3] Game structure design

In order to teach CNN's principle of extracting feature values by applying filters to the entered images, this board game applies a rule that reduces the range of boards by finding the largest number of characters on the board. Through this process, the learning principle of artificial intelligence can be learned naturally.

[Step 4] Game material design

To play the board game, students need boards with various characters on it and a user manual. Teachers may choose any character that they want to draw on the board.

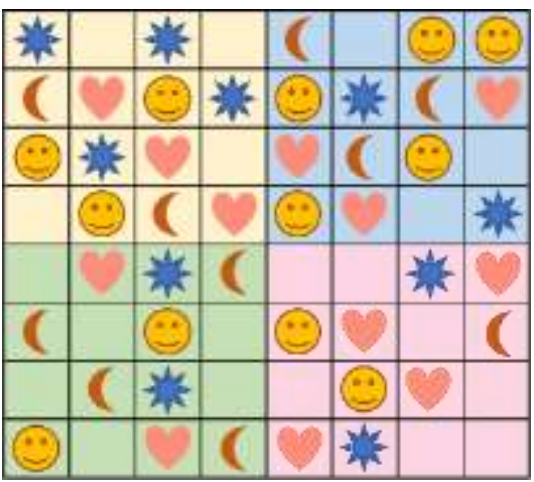

Figure 1 Board sample

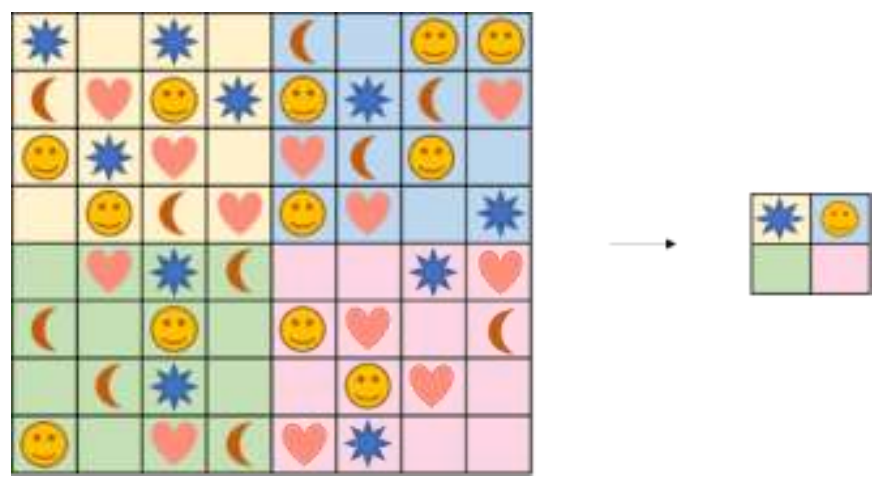

Figure 2 Example of the result by max

[Step 5] Set the game rule. (see figure 2).

- Use $8 * 8$ boards combined with four $4 * 4$ boards in different colors.

- Fill out the blanks on the boards. The Teacher can use any characters that they want, such as star, square, triangle, and circle shape.

- Find the most characters in each color and compress the $8 * 8$ board into a $2 * 2$ board. The $2 * 2$ shaped board made in this way is referred to as "Max". The students can learn Max pooling from this process.

- This time, put the $2 * 2$-shaped filter into one of the $4 * 4$ boards in order. Find the most characters in the filter and compress the four $4 * 4$ boards into four $3 * 3$ boards. Repeat this process two more times, make a $2 * 2$ board. And this $2 * 2$-shaped board is referred to as "Criteria". The students are able to learn how stride works in CNN.

- Repeat the above procedure to obtain the result values for max and filter.

- The closer the result value obtained is to the criteria, the higher the rank can be obtained, and the scores are assigned for each rank.

[Step 6] Test and Correction. (see figure 3).

Educate by utilizing the board games produced, and correct any problems found in the process. Afterward, correct the problems to study more complete methods of education $[5,6]$.
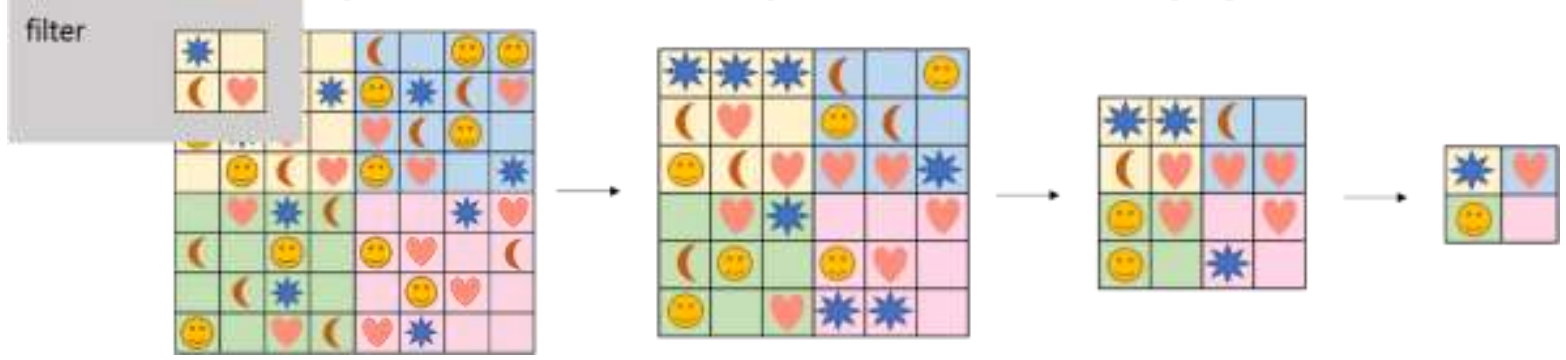

Figure 3 Example of the result by filter

3.2 AI instructional design model

[Step 1] Set the learning objective

Target on understanding the importance of AI education and AI learning principle. 
[Step 2] Analyze assignment tasks

To provide students with a sense of accomplishment based on mission achievement, various sub-tasks are constructed from the learning objective. Add the missions in the sub-tasks and let the complete student missions orderly. After playing the AI game, check the achievement process of students and measure the degree of achievement(see figure 4)

[Step 3] Analyze entry behaviors and learner traits

Analyze learner traits about AI through a mindmap, and design the course based on the learner characters analyzed.

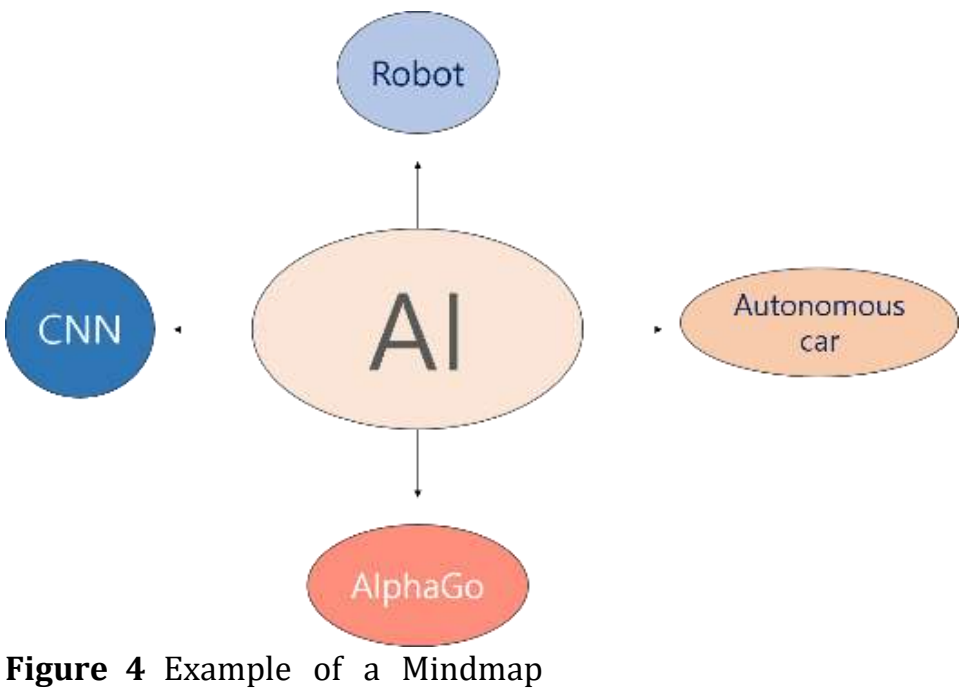

[Step 4] Speak the purpose of the mission

After playing the game, students need to speak the AI principles in the game. In terms of the nature of gamification, rewards should be given to students who correctly articulate the principles.

[Step 5] Criterion-referenced assessment

Observe and evaluate learners' participation in the game and the learners' presentation on the principles.

[Step 6] Develop a teaching method

For gamified education, apply the game elements such as goals, challenges, quests, feedback, Accrual grading, and Storytelling, Etc in the course(see figure 5).

[Step 7] Develop and select teaching material

Create learning materials available for classes to help students understand AI principles, which are the course's learning goal, and to link the materials with the game so that students can have a higher learning effect. Besides, make learning materials simply and colorfully in order that students can learn difficult concepts with fun.
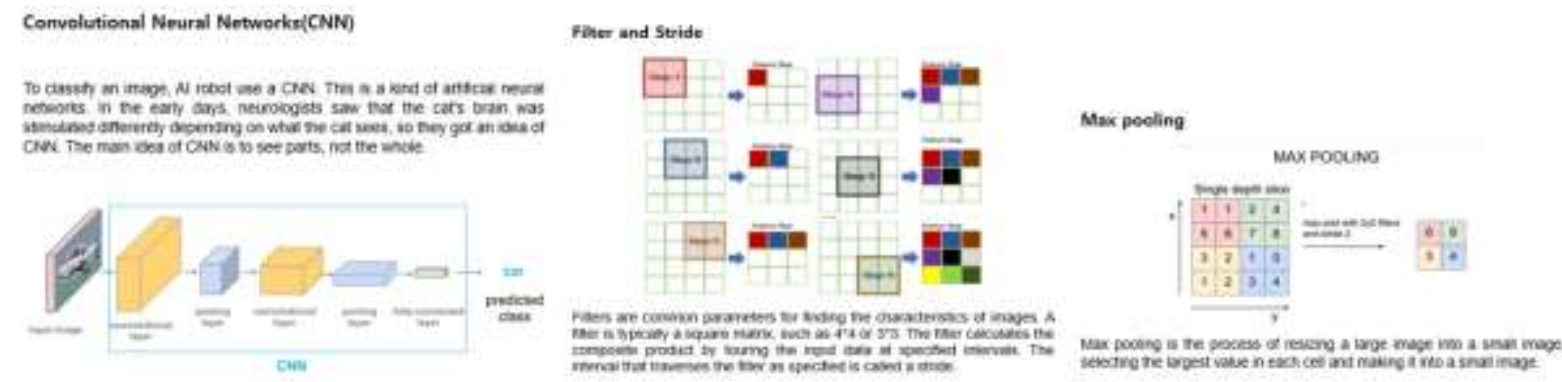

Figure 5 Teaching materials for the class

[Step 8] Modify the course

Get feedback on problems found during the course.

[Step 10] Comprehensive assessment

Analyze the effectiveness of education by evaluating how much students' understanding has increased through games and the learning materials[7,8,9]. 


\section{Demonstration of suggested gamification education}

The curriculum was conducted for the elementary school to verify the developed curriculum and teaching methods' effectiveness. The satisfaction and understanding of the curriculum were investigated and analyzed. We trained 152 students to improve their understanding of AI principles playing AI games and using the teaching materials we suggested in this study. The Likert 5-point scale is used on the survey. The satisfaction survey results showed that 152 students, on average, had an understanding of $92 \%$ and satisfaction of $4.73[10]$. (see table 3, table 4).

Table 3 Specific areas of satisfaction and understanding

\begin{tabular}{ll}
\hline Satisfaction & Understanding \\
\hline 1. Interest & \\
2. Participation in activities & \\
3. Level of content & 1. AI \\
4. Information & 2. AI principles \\
5. Expectation & 3. CNN \\
6. Cognition & 4. AI working process \\
7. Intention of higher education &
\end{tabular}

Table 4 The result of survey by areas

\begin{tabular}{ll|ll|l}
\hline Number of students & \multicolumn{2}{l}{ Satisfaction } & \multicolumn{2}{l}{ Understanding } \\
\hline & 1 & 96 & 1 & 4.41 \\
& 2 & 94 & 2 & 4.83 \\
152 & 3 & 85 & 3 & 4.78 \\
& 4 & 92 & 4 & 4.90 \\
& 5 & 92 & & \\
& 6 & 93 & & \\
\hline Average & 7 & 92 & & \\
\hline
\end{tabular}

\section{Conclusions}

$\mathrm{AI}$, a new industry that has been in the spotlight in the recent Fourth Industrial Revolution, is a musttell technology for children who will live in the future. In a situation where no one knows how much artificial intelligence will develop, it is imperative for our children to educate them to live by using AI. Thus, this paper proposed how to teach elementary school students to learn AI through games. The proposed educational measures could arouse students' interest in AI and positive motivation for learning, and the satisfaction and understanding of the suggested teaching methods were also investigated at a high level. We hope that this paper will lead to more active research on the education method of sophisticated technologies with interest.

\section{Acknowledgements}

This work was supported by the Ministry of Education of the Republic of Korea and the National Research Foundation of Korea(NRF-2019S1A5C2A04083374). And, this work was supported by the Korea Foundation for the Advancement of Science and Creativity(KOFAC) grant funded by the Korea government(MOE). 


\section{References}

[1] Cheong C, Cheong F, Filippou J. Quick quiz: A gamified approach for enhancing learning. PACIS [Internet]. 2013 [cited 2020 Sep 29]; Available from: https://www.semanticscholar.or $\mathrm{g} /$ paper/438ebea976185003c4ff0658a4313922aaf86154

[2] Turan Z, Avinc Z, Kara K, Goktas Y. Gamification and education: Achievements, cognitive loads, and views of students. Int J Emerg Technol Learn. 2016;11(07):64.

[3] Touretzky D, Gardner-McCune C, Martin F, Seehorn D. Envisioning AI for K-12: What should every child know about AI? Proc Conf AAAI Artif Intell. 2019;33:9795-9.

[4] Yu Y, Chen Y. Design and development of high school artificial intelligence textbook based on computational thinking. OAlib. 2018;05(09):1-15.

[5] Livingston SA. Introduction for the social studies teacher. New York: Free Press; 1973.

[6] Kim J, Park N. Development of a board game-based gamification learning model for training on the principles of artificial intelligence learning in elementary courses. J Korean Assoc Inf Educ. 2019;23(3):229-35.

[7] Murray N, Perronnin F. Generalized Max Pooling. In: 2014 IEEE Conference on Computer Vision and Pattern Recognition. IEEE; 2014.

[8] Guo C, Liu Y-L, Jiao X. Study on the influence of variable stride scale change on image recognition in CNN. Multimed Tools Appl. 2019;78(21):30027-37.

[9] Jonassen DH. Instructional design models for well-structured and III-structured problem-solving learning outcomes. Educ Technol Res Dev. 1997;45(1):65-94.

[10] Dichev C, Dicheva D, Agre G, Angelova G. 10. Gamification in Education: A Systematic Mapping Study. Journal of Educational Technology \& Society. 2015;18(3):1-10. 